\title{
Validation and Translation of the Greek Version of the "DCDDaily-Q-GR" Questionnaire
}

\author{
Georgia Dragoumanaki ${ }^{1}$, Athina Patelarou1, Pelagia Vorgia ${ }^{2,3}$, Dimitra Sifaki-Pistolla1,4, \\ Evridiki Patelarou1 \\ ${ }^{1}$ Department of Nursing, Hellenic Mediterranean University, Heraklion, Greece \\ ${ }^{2}$ Department of Mother and Child, Medical School, University of Crete, Heraklion, Greece \\ ${ }^{3}$ Institute of Afri-Food and Life Sciences, University Research Centre, Hellenic Mediterranean University, Heraklion, Greece \\ ${ }^{4}$ Department of Social Medicine, School of Medicine, University of Crete, Heraklion, Greece \\ Email: dragoumanakigeorgia@gmail.com
}

How to cite this paper: Dragoumanaki, G., Patelarou, A., Vorgia, P., Sifaki-Pistolla, D. and Patelarou, E. (2021) Validation and Translation of the Greek Version of the “DCDDaily-Q-GR" Questionnaire. Health, 13, 1222-1241.

https://doi.org/10.4236/health.2021.1311090

Received: October 10, 2021

Accepted: November 12, 2021

Published: November 15, 2021

Copyright (c) 2021 by author(s) and Scientific Research Publishing Inc. This work is licensed under the Creative Commons Attribution International License (CC BY 4.0)

http://creativecommons.org/licenses/by/4.0/

\begin{abstract}
The origin of Developmental Coordination Disorder (DCD) has not been clarified yet. DCD is considered as a movement disorder that may strongly affect child's Activities of Daily Living (ADL). Reliable evaluation tools for young DCD are importantly useful. This study aimed to translate and validate the Developmental Coordination Disorder Daily Questionnaire (DCDDaily-Q) into Greek. The current validation study reports on the translation, cultural adaptation and validation of the Greek. The total sample consisted of 191 children (age 5 - 8 years) and their parents who completed the questionnaire as a reference group. The participants were randomly divided into two groups. The first group (100 parents) completed only the DCDDaily-Q. The second group consisted of 91 parents who completed the DCDDaily-Q, while their children were additionally evaluated with the Movement Assessment Battery for Children 2 (MABC-2). Then two groups were created that included (25) children with DCD and a control group 30 children with typical developmental. The results were analyzed was performed using IBM SPSS statistics $24.0(\mathrm{a}=0.05)$. The internal consistency of the Greek version of the DCDDaily-Q was assessed (Cronbach's $\alpha=0.86$ ). High test-retest reliability for all items and good diagnostic performance for identifying children with DCD were achieved with a sensitivity of 0.76 and a specificity of 0.67 . The Greek version of DCDDaily-Q was proved to be a reliable and valid screening tool for ADL assessment in 5 to 8 year old children with DCD; offering an easy to use and economical tool in the Greek healthcare system.
\end{abstract}

\section{Keywords}

Activities of Daily Living, Assessment, DCDDaily-Q, Developmental Coordination Disorder, Validation 


\section{Introduction}

The terms Developmental Coordination Disorder (DCD according to the DSM5) [1] or Specific Developmental Coordination Disorder (SDCD according to ICD-10) [2] are used to describe children with motor difficulties that may affect their ability to perform daily routine activities according to their age [3]-[9]. These may include for instance, leisure playing as craftwork constructing, ball playing skills, bike riding as well as personal hygiene skills such as eating and dressing, as well as handwriting performance may also be affected [3] [9].

The DCD [1] and SDCD [2] have similar diagnostic criteria. According to the Diagnostic and Statistical Manual of Mental Disorders Text Revision (DSM-5) [1], DCD is a movement disorder characterized by an evident impairment in the development of motor coordination. A diagnosis is made if the impairment significantly interferes with activities of daily living; if the movement disorder is unrelated to a medical condition such as cerebral palsy or muscular dystrophy, or fails to meet the criteria for other developmental disorder [1] [4].

DCD is a disorder which may comorbid with one or more other Neurodevelopmental Disorders such as Attention Deficit Hyperactivity disorder (ADHD) and Learning Difficulties [1] [2] [10]. The estimated prevalence of DCD among school-age children worldwide is around 5\% - 6\% and the boys/girls ratio are 2:1 [10] [11] [12]. This notable burden deserves prompt attention, due to the fact that DCD is a lifelong disability where symptoms continue in adulthood [4] [13]. Therefore reliable identification and monitoring of this specific and common disorder using early intervention programs should be a major priority of the primary public health and education [4].

Towards this direction, valuating DCD could be achieved using either motor test tools or standardized screening questionnaires [14] [15]. Motor test tools constitute a significant time consuming and expensive control approach for both children and performers, [14] whereas utilization of a standardized reliable screening tool could offer an efficient cost-effective solution [4]. If the use of a such questionnaire is fully incorporated in routine clinical DCD assessment, the probable DCD cases could then be confirmed by selective application of movement tests [14] [15] [16].

The sole parent reporting instrument, developed for DCD and daily activities of living is the Developmental Disorders of Coordination Daily Questionnaire (DCDDAILY-Q) [17] [18] developed in the Netherlands. The DCDDAILY-Q is a fast 23-item questionnaire that was developed to address motor performance in children aged 5 to 8 years old, quickly in a comprehensive range of activities of daily living. The questionnaire has already been tested and is considered reliable since it showed moderate to high internal consistency, with a Cronbach's alpha coefficient of 0.76 for "Participation", 0.85 for "Quality", and 0.94 for Acquisition" demonstrating, $88 \%$ Sensitivity and $92 \%$ Specificity [19]. It has also been associated with other movement tests (including the Movement Assessment Battery for Children, MABC-2) [17] and its high discriminant function 
makes it suitable as a screening tool for DCD [15].

Such tools may play an integral role in public health and clinical practice therefore they should be standardized into multiple cultural environments or diverse healthcare systems; focusing on countries of low-middle healthcare resources or with lack of such cost-effective screening solutions [20]. Greece and other European countries have such healthcare. We strongly believe that validation and utilization of a parental questionnaire in Greece may contribute to early identification of children at risk, enhance the assessment of motor coordination problems and lead the design of targeted effective interventions to control DCD among young children.

The present study attempted to standardize the DCDDAILY-Q in Greek, as an effort to fill this gap in the healthcare. Main objectives were the translation the cultural and its final validation. Finally, all psychometric properties of the Greek version questionnaire (internal consistency, validity, diagnostic sensitivity and specificity) were calculated.

\section{Methods}

\subsection{Study Design and Population}

This validation study followed the international guidelines [21] for translating, culture adaptation and tools and questionnaires validation. The study sample consisted of children aged from 5 to 8 years old and their parents, all residents of Heraklion, Crete, Greece. The study was a cross-sectional study conducted from November 2018 to May 2019, after first obtaining the necessary permits to approve the survey from the relevant committees of hospitals, the Community Center of Mental Health for children and adolescences, "Venizeleio and Pananio" General Hospital of Heraklion (license number: 81/2018), the General University Hospital of Heraklion (license number: 107/2018) and a competent body of the Ministry of Education to Children from schools in the prefecture (license number: F.15/183019/201118/D1, 22-11-2018) of Heraklion who had the criteria to enter the study were included as a reference group, as a control group and as a clinical group.

\subsection{Measures}

\section{$D C D D A I L Y-Q$}

The DCDDAILY-Q developed by Van der Linde et al. [7] was used as the core tool for translation and validation for screening DCD in Greek population. It's a 23-item (P1 - 23) parental questionnaire designed to address children's performance in a broad range of three scales ADL.

First the "self-care and self-maintenance". For example: Activity $\rightarrow$ Pouring juice (Correct performance: Controlled motions, without spilling or hitting the glass/ table or dropping the cap, neatly opening and closing the bottle/ container, at a normal pace). Parents respond to the activity using the following three subscales: 


\begin{tabular}{lll}
\hline \multicolumn{1}{c}{ Participation } & \multicolumn{1}{c}{ Quality } & \multicolumn{1}{c}{ Acquisition } \\
\hline My child does this... & \multicolumn{1}{c}{ My child can do this... } & \multicolumn{1}{c}{ My child... } \\
\hline 1. regularly & $\square$ 1. well & \\
$\square$ 2. sometimes & $\square$ 2. sometimes well and at & $\square$ is taking or has taken \\
$\square$ 3. seldom & other times not as well & longer to learn this skill \\
$\square$ 4. not yet/never & $\square$ 3. not very well (or badly) & than his/her age peers \\
& most of the time & \\
\hline
\end{tabular}

Second the "productivity and schoolwork". For example: Activity $\rightarrow$ Cutting paper (Correct performance: Controlled cutting motions along the (pre-printed) lines, at a normal pace). Parents respond to the activity using the following three subscales:

\begin{tabular}{|c|c|c|}
\hline Participation & Quality & Acquisition \\
\hline My child does this... & My child can do this... & My child... \\
\hline $\begin{array}{l}\square \text { 1. regularly } \\
\square \text { 2. sometimes } \\
\square \text { 3. seldom } \\
\square \text { 4. not yet/never }\end{array}$ & $\begin{array}{l}\square \text { 1. well } \\
\square \text { 2. sometimes well and at } \\
\text { other times not as well } \\
\square \text { 3. not very well (or badly) } \\
\text { most of the time }\end{array}$ & $\begin{array}{l}\square \text { is taking or has taken } \\
\text { longer to learn this skill } \\
\text { than his/her age peers }\end{array}$ \\
\hline
\end{tabular}

Third and last one the "leisure and play". For example: Activity $\rightarrow$ Playing Hopscotch (Correct performance: Controlled, fluent motions, ending on one foot within the lines of the correct square, without loss of balance or falling over, at a normal pace)

\begin{tabular}{lll}
\hline \multicolumn{1}{c}{ Participation } & \multicolumn{1}{c}{ Quality } & \multicolumn{1}{c}{ Acquisition } \\
\hline My child does this... & \multicolumn{1}{c}{ My child can do this... } & \multicolumn{1}{c}{ My child... } \\
\hline & $\square$ 1. well & \\
$\square$ 1. regularly & $\square$ 2. sometimes well and & $\square$ is taking or has taken \\
$\square$ 2. sometimes & at other times not as well & $\begin{array}{l}\text { longer to learn this skill } \\
\text { than his/her age peers }\end{array}$ \\
$\square$ 3. seldom & $\square$ 3. not very well (or badly) & \\
$\square$ 4. not yet/never & most of the time & \\
& &
\end{tabular}

It was designed to be completed by parents of five to eight years old children. Parents calculate their child's performance on a three-point scale for each item ( 1 = good, 2 = medium, 3 = poor $)$ when describing their children's ADL.

The DCDDaily-Q total score is the sum of the 23 item scores, ranging from 23 (good) to 69 (poor). The questionnaire was designed so as each item can be marked "good" when the child usually performs the activity without trouble, and "poor" when the activity can usually not be performed without dropping things, knocking things over, or falling, or when the child is not able to complete the activity. The total score indicates whether the child is in the group of children with "indicated, or suspected DCD", or "probably not DCD". The questionnaire takes 
15 minutes to be completed [19].

\section{$M A B C-2$}

The MABC-2 test is a widely accepted approach [22] which identifies children motor difficulties related to the first diagnostic criterion for DCD. The test is administered by special education therapists. Firstly created by Pearson [23], is the reference template or the gold standard for definite the diagnosis of children with developmental motor coordination disorder [22] [23] [24] [25].

It has been designed for children aged from 3 to 16 years old in order to classify them according to the degree of their motor impairment (scores ranging from 0.1 to 99). The higher score indicates good performance, while scores under the $<5$ th percentile classified as motor impairment. A score between 5 and the 16th percentile is at risk for motor difficulties [20] [21]. The MABC-2 performance test has a moderate to good construct and convergent validity. The specificity appears to be good and the sensitivity is moderate to good depending on the selected deviation (good sensitivity using the 15th percentile scale). Studies on MABC-2 show good to excellent reliability and good to excellent testretest reliability [22] [23].

\subsection{Translation and Cross-Cultural Adaptation}

The DCDDAILY-Q was translated according to the guidelines developed [26] for cross-cultural adaptation of assessment instruments. The standardization of evaluation tools follows certain rules when designing a research [21]. The aim of this process followed was to obtain different language versions of the English questionnaire, which are conceptually equivalent to the target culture. Obviously, the tool must be equally natural and acceptable it also must be exercised in the same way. The goal was to achieve intercultural and conceptual approach than the linguistically equivalence.

The implementation of this method involves the following steps (Figure 1) [26].

In the first place there was a forward translation into Greek. Two independent translators were selected for the translation from English to Greek language; a health professional and an English teacher. Both were familiar with the questionnaire terminology, professional English-speakers and Greek native speakers. Instructions were given to the translation approach, emphasizing conceptual rather than literal translations, as well as the need to use natural and acceptable language for the wider Greek public. It was followed by a team of experts including the original translators, five health experts, a pediatric neurologist, a pediatrician, a physiotherapist, pediatric occupational therapist and a pediatric psychologist, all with over twenty years of experience in their field. The team of scientists was invited by the principal researcher (first author) to identify and resolve inadequate expressions between the two translations, as well as any discrepancies between future translation and existing or comparable previous versions of the questions. Using the same approach as described in step one, the questionnaire that emerged from the previous phase was again translated into 


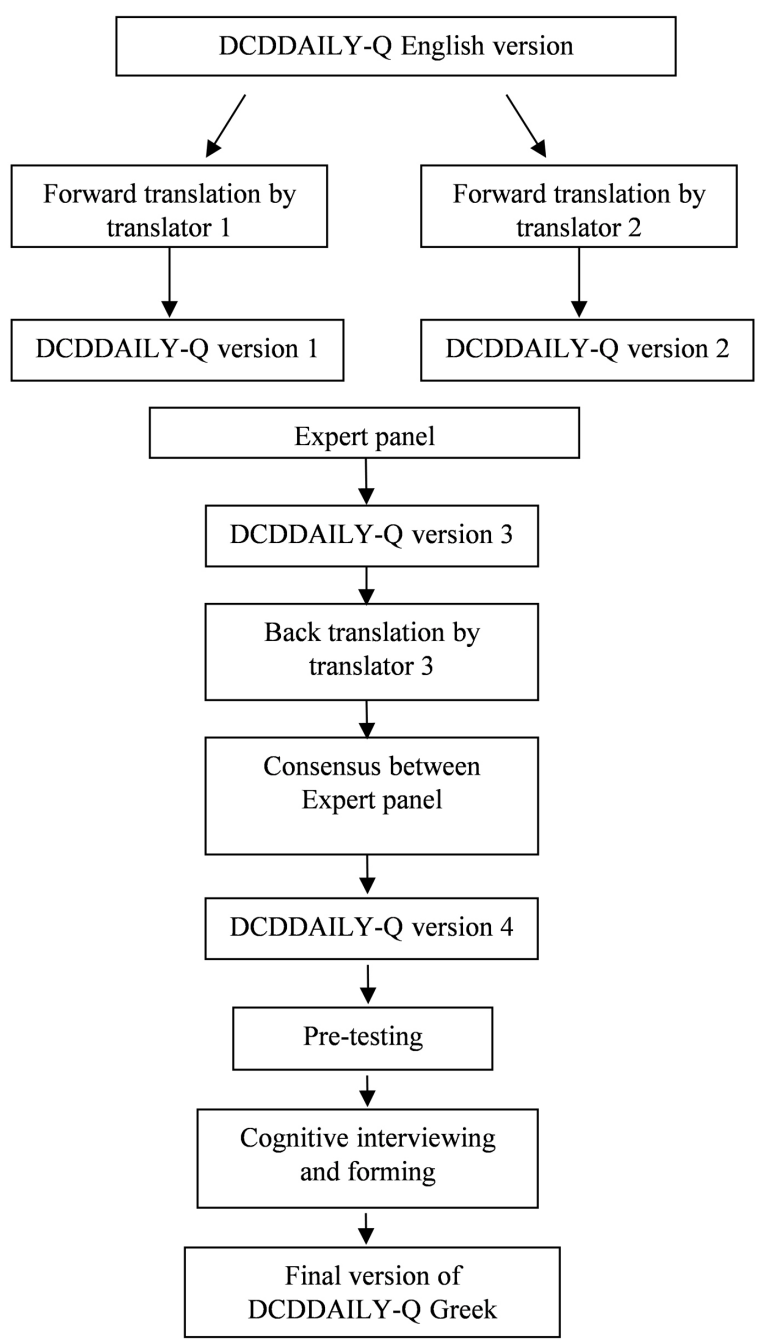

Figure 1. Steps of translation and cross-cultural adaptation.

English (back-translation). Another translator double language native speaker (English and Greek) was conducted this process. This translator had not received the questionnaire in its original form. As in the forward translation, the emphasis on backward translation was on conceptual and cultural equivalence rather than linguistic one. Particularly problematic words or phrases were not captured.

The pre-definitive version was field-tested by an occupational therapist who worked in pediatric and pediatric neurologist settings with a sample of 13 parents. Parents were asked to identify words, phrases, expressions, concepts that were unclear. Based on their input, the committee modified the pre-definitive version. Pre-tests and cognitive interviews were then conducted to complete the cultural adjustment. Respondents participated in this phase filled in the questionnaire coupled with a demographic sheet. Participants were parents of children who attended primary education, aged from 5 to 8 years old, without any diagnosed developmental, neurological and visual disorders [1]. A total of 13 parents of different socio-economic groups were enrolled. Prior to the test, they 
were informed of its completion instructions and a serial number was assigned to each version [26].

Respondents were then asked to think and ask questions where they considered appropriate. For example, if they could repeat the question in their own words, what came to their mind first when they heard a particular phrase or term. They were then asked to explain how they choose their answer. These questions were repeated for each item. They were also asked about any words they did not understand as well as any words or expressions they considered not to make sense in Greek or represent the Greek culture. To determine and finalize the questionnaire, a pilot study was conducted to interpret: 1) whether the questions asked were simple and easy to understand (this was done to ensure that participants didn't leave questions unanswered) and 2) whether the design of the study will produce the desired statistical results. The same parents were asked to fill in the questionnaire once again after 15 days of their primary attempt (test-retest) to detect the repetition of their responds.

\subsection{Validation and Quantitative Indicators}

A total of 191 children participated and finally completed the DCDDaily-Q-GR. Their guardians have previously signed the consent forms. Ninety one participants (47.6\%) of them were also assessed with the Movement Assessment Battery for Children (2) test (total score lower than $15^{\text {th }}$ percentile) to assess children's motor performance. Participants of the clinical group that were assessed with MABC-2 consisted of 25 children (28.5\%) diagnosed with DCD. Their parents completed the DCDDAILY-Q-GR. These children were selected from the Community Center of Mental Health for children and adolescences, "Venizeleio and Pananio" General Hospital of Heraklion and the General University Hospital of Heraklion.

The control group included 30 children of typical development aged from 5 to 8 years old coming from the first grades of primary education in Heraklion prefecture. The inclusion criteria were to have no history of preterm birth (before 37 weeks of gestation). Children with neurodevelopmental or neurological disorders, such as speech disorders, cerebral palsy, autistic spectrum disorder, intellectual disability, hearing or vision problems and epilepsy were excluded. Parents of the control group were asked to participate by completing the DCDAILY$\mathrm{Q}$ and their children were assessed with the MABC2. The remaining 100 children in the study whose parents completed only the questionnaire were the reference group.

\subsection{Statistical Analysis}

Statistical analysis was performed with the IBM SPSS Statistics 24.0, while all tests were two-sided and implemented at alpha level 0.05. Descriptive statistics were estimated and expressed as frequencies of the response and the corresponding percentages of the valid responses and means with standard deviations (mean, SD) or median with minimum-maximum values (median, min-max). 
Internal consistency of the pilot study (test-retest) and the main study was measured using the Cronbach's alpha coefficient for all 23 items. The test for the difference of mean values of continuous variables of both gender and groups (Clinical, Control and Reference) was done with independent samples t-test, or paired samples t-test depending on whether the groups were independent or couples. One-way ANOVA followed by post hoc test using Tukey HSD to find individual differences between groups. Chi-square test for relevance tables was applied to test the correlation between two discrete variables. The Pearson's rho coefficient was used to explore and identify correlations between two continuous variables. ROC analysis was followed to assess sensitivity and specificity.

\section{Results}

\subsection{Sample Characteristics}

One hundred ninety-one (191) participants completed the DCDDaily-Q-GR. Ninety-one (47.6\%) of them were also assessed with the Movement Assessment Battery for Children-2 test. The sample included 25 children (28.5\%) diagnosed with DCD. The largest percentage of all participants were boys $(n=107,56.0 \%)$. There was a statistically significant difference in age distribution between the groups with DCDDAILY-Q-GR and DCDDAILY-Q-GR \& MABC-2 (p = 0.017). Children aged from 5 to 6 years old whose parents' completed DCDAILY-Q-GR and were evaluated by the occupational therapist with MABC-2 were 34 (63.0\%), significantly more than the children with DCDDaily-Q-GR alone who were 20 (37.0\%) while the opposite was observed for the children aged from 7 to 8 years old. A higher percentage of boys $(n=107,56.0 \%)$ participated in the study while the enrolled girls were $44.0 \%[(\mathrm{n}=84)$ (ratio 1.3:1.0)] (Table 1).

Table 1. Age and grades for participants.

\begin{tabular}{|c|c|c|c|c|c|c|c|c|}
\hline & & \multicolumn{4}{|c|}{ Groups } & \multirow{2}{*}{\multicolumn{2}{|c|}{ Total }} & \multirow{3}{*}{$\mathbf{P}$} \\
\hline & & \multicolumn{2}{|c|}{$\begin{array}{c}\text { Only } \\
\text { DCDDAILY-Q-GR }\end{array}$} & \multicolumn{2}{|c|}{ DCDDAILY-Q-GR + MABC } & & & \\
\hline & & $\mathrm{n}$ & $\%^{1}$ & $\mathbf{n}$ & $\%^{1}$ & $\mathbf{N}$ & $\%^{2}$ & \\
\hline \multirow{2}{*}{ Gender } & Boy & 55 & $51.4 \%$ & 52 & $48.6 \%$ & 107 & $56.0 \%$ & 0.766 \\
\hline & Girl & 45 & $53.6 \%$ & 39 & $46.4 \%$ & 84 & $44.0 \%$ & \\
\hline \multirow{3}{*}{ Age } & $5-6$ & 20 & $37.0 \%$ & 34 & $63.0 \%$ & 54 & $28.3 \%$ & 0.017 \\
\hline & $6-7$ & 32 & $53.3 \%$ & 28 & $46.7 \%$ & 60 & $31.4 \%$ & \\
\hline & $7-8$ & 48 & $62.3 \%$ & 29 & $37.7 \%$ & 77 & $40.3 \%$ & \\
\hline \multirow{3}{*}{$\begin{array}{l}\text { Educational } \\
\text { level }\end{array}$} & Kindergarten & 21 & $38.2 \%$ & 34 & $61.8 \%$ & 55 & $28.8 \%$ & 0.020 \\
\hline & $1^{\text {st }}$ grade of Primary School & 30 & $51.7 \%$ & 28 & $48.3 \%$ & 58 & $30.4 \%$ & \\
\hline & $2^{\text {nd }}$ grade of Primary School & 49 & $62.8 \%$ & 29 & $37.2 \%$ & 78 & $40.8 \%$ & \\
\hline
\end{tabular}

$1=$ Percentage per line; 2 = Percentages per column. 


\subsection{Descriptive Statistics}

The descriptive statistics of the DCDDaily-Q-GR questionnaire for all three parts, Participation $(\mathrm{Q})$, Quality $(\mathrm{Q})$, and Learning present for Participation in most of the activity choices show a floor effect. With high percentages in the "Regularly" option ranging from $37.4 \%(\mathrm{n}=70)$ in question P20 to $96.3 \%(\mathrm{n}=$ $184)$ in question P6. High percentages in the "Sometimes" option showed activities P1 $(\mathrm{n}=86,45.7 \%), \mathrm{P} 2(\mathrm{n}=64,33.9 \%)$ and S9 $(\mathrm{n}=71,37.2 \%)$. "Seldom" there were no high response rates. Two of the activities, P19 and P23, represented $37.4 \%(\mathrm{n}=71)$ and $36.3 \%$ in the "not yet/never" option (A.1). Results for the DCDDaily-Q-GR "Quality" Questionnaire section show that "Well” in performance quality was the dominant in all activities except Q2 and Q19 that had higher percentages in "Sometimes well and at other times not as well" (Q2: $\mathrm{n}=$ 88, 54.7\%; Q19: $\mathrm{n}=51,38.1 \%$ ) (A.2). "Acquisition" showed that rates in all activities ranged from $87.5 \%(n=161)$ for the A19 process to $96.3 \%(n=184)$ for the A3, A5, A12, A16 processes (A.3). The scales for the total score of the "Participation" questionnaire were averaged $30.8 \pm 5.4$ with a range of $21-46$. Correspondingly for the "Quality" Questionnaire section the mean value was $29.4 \pm$ 5.7 with a range of $18-54$ and for the "Acquisition" questionnaire it was $1.5 \pm$ 3.6 with a range of $0-23$ (Appendix).

\subsection{Reliability}

Internal consistency and reproducibility (test-retest reliability) were measured as part of the reliability analysis of the translated instrument. Internal consistency was determined by Cronbach's alpha. The pilot study was done and Cronbach's coefficients calculated on the Participation (P), Quality (Q) and Acquisition (A) scales of the questionnaire showed high internal consistency values with Cronbach's alpha values of 0.882 for the scale (P), 0.797 for the scale (Q) and 0.850 for scale (A) acceptable since it is above the limit of 0.700 .

In the main study the internal consistency of the questions was high for the overall scales with values of $\mathrm{a}=0.833$ (Participation), $\mathrm{a}=0.857$ (Quality) and $\mathrm{a}=$ 0.927 (Acquisition). Of the remaining subscales with the exception of "Participation-Fine motor", "Participation-Self-Care/Self-maintenance)" and "Quality-Fine motor" (Table 2).

\subsection{Scale Correlations}

The correlation test between the scales and the subscales of "Participation" showed in many cases a moderate to strong correlation in all cases with $r$ values ranging from 0.2298 (Participation - Fine motor with Self-Care/Self-maintenance) to 0.829 (Participation - Fine motor with Participation - Total Quality). In the relation of the "Participation" scales to the "Quality" scales, all the variables that were correlated were in the lower range with values $r=0.179$ (Self-care/self-maintenance, Participation and Quality) to $r=0.452$ (Total Quality with Participation-Fine motor). Correlations of the (sub) scales were significant but low of "Participation" with "Acquisition" $(r<0.323)$ with the only 
Table 2. Descriptive statistics of the DCDDaily-Q-GR questionnaire for scales, and Cronbach- $\alpha$.

\begin{tabular}{cccccccc}
\hline & & A & SD & M & Min & Max & Alpha \\
\hline \multirow{4}{*}{ Participation } & Fine motor & 9.0 & 2.1 & 9.0 & 5 & 18 & 0.687 \\
& Self-Care/Self-maintenance & 13.3 & 2.6 & 13.0 & 7 & 23 & 0.674 \\
& Play/Gross motor & 8.5 & 2.8 & 8.0 & 2 & 15 & 0.706 \\
& Total Participation & 30.8 & 5.4 & 30.0 & 21 & 46 & 0.833 \\
\hline \multirow{4}{*}{ Quality } & Fine motor & 9.0 & 2.3 & 8.0 & 5 & 19 & 0.648 \\
& Self-Care/Self-maintenance & 12.7 & 2.5 & 12.0 & 7 & 23 & 0.755 \\
& Play/Gross motor & 7.7 & 2.5 & 7.0 & 1 & 15 & 0.737 \\
& Total Quality & 29.4 & 5.7 & 28.0 & 18 & 54 & 0.857 \\
\hline \multirow{3}{*}{ Acquisition } & Fine motor & 0.4 & 1.2 & 0.0 & 0 & 7 & 0.873 \\
& Self-Care/Self-maintenance & 0.6 & 1.6 & 0.0 & 0 & 10 & 0.823 \\
& Play/Gross motor & 0.5 & 1.2 & 0.0 & 0 & 6 & 0.841 \\
& Total Acquisition & 1.5 & 3.6 & 0.0 & 0 & 23 & 0.927 \\
\hline
\end{tabular}

$\mathrm{A}=$ Average, $\mathrm{SD}=$ Standard Deviation, $\mathrm{M}=$ Median, Min. $=$ Minimum, Max. $=$ Maximum, Alpha = Cronbach's alpha.

non-correlated Scale of "Participation-Play/Gross motor" with "Acquisition-Fine motor" ( $\mathrm{r}=0.133, \mathrm{p}=0.07$ ). The Activities of Daily Living (ADL) Scales showed moderate to strong correlation and range of correlations from $r=0.35$ (Quality-Game/Gross Motor with Self-Care/Self-maintenance) to $r=0.818$ (Self-Care/ Self-Maintenance). Similarly, all scales of "Quality" were correlated with "Acquisition" with lower correlation values $r=0.264$ (Play Quality/Cross Motor with Acquisition-Fine Motor), up to $r=0.567$ (Quality-Fine motor with Acquisition-Fine Motor).

\subsection{Discriminative Performance Total Scales}

Demographic and Learning Factors' DCDDaily Scales, boys had a higher mean score on the $37.5 \pm 7.7$ "Participation" scale than girls (35.2 to 6.3) at $\mathrm{p}=0.031$, while on the Quality scale the mean values were $30.3 \pm 6.1$ for boys and $28.3 \pm$ 5.0 for girls $(\mathrm{p}=0.020)$. There was no statistical significant difference between the sexes on the gender "Acquisition Scale" ( $p=0.433$ ). The effect of age was seen between the ages $5-6,6-7$ and $7-8$ where there was a statistically significant difference $(\mathrm{p}=0.002)$ on the "Participation" scale and $\mathrm{p}<0.001$ on the "Quality" and "Acquisition" scales. In addition on all 3 scales the mean decreases as age increases. The decrease in the values of the "Participation", "Quality" and "Acquisition" scales showed a statistically significant difference for each class of study ( $p<0.001$ ). Subjective parenting of children by language lesson did not show statistically significant differences for any of the DCDDaily-Q scales ( $p$ > 0.05). The "Quality" Scale shows statistically significant differences in Mathe- 
matics performance $(\mathrm{p}=0.015)$ with mean values of $28.8 \pm 5.1$ (average level), $29.9 \pm 5.4$ (good) and $27.3 \pm 4.2$ (Very good/Excellent). Declining mean scores on the "Participation" scale were presented for Gymnastics performance with $\mathrm{p}$ $=0.004$, "Quality" with $\mathrm{p}<0.001$ and "Acquisition" with $\mathrm{p}=0.010$. The level in the writing mode only differentiates the "Quality" Scales with $\mathrm{p}=0.041$ and the "Acquisition" Scale with $\mathrm{p}=0.041 .3 .6$ (A.4). Predictive validity DCDDAILY-Q gave good predictive validity and correctly classified all children according to clinical diagnosis.

The diagnostic characteristics (e. g sensitivity, specificity) of the DCDDaily-Q questionnaire were assessed in the form of ROC analysis on a total of 66 children who had completed both assessment tools. The ROC analysis was performed with two approaches: 1) The total of children (A.5), 2) By age group (5 - 6, 6 - 7, 7 - 8 years).

Setting $>30$ to the DCDDaily-Q "Quality" Scale threshold and the 15th percentile to the MABC-2 Scale show that the sensitivity of the method is $0.76 \%$ to 95\%, DO: $0.61-0.87$, while the specificity $0.67 \%$ to $95 \%$, DE: $0.51-0.80$ (Figure 2).

The positive predictive values (PPV) are 0.700 (95\% DE: $0.55-0.82)$, while the negative predictive values (NPV) are 0.73 (95\% DE: 0.57 - 0.85) (Table 3).

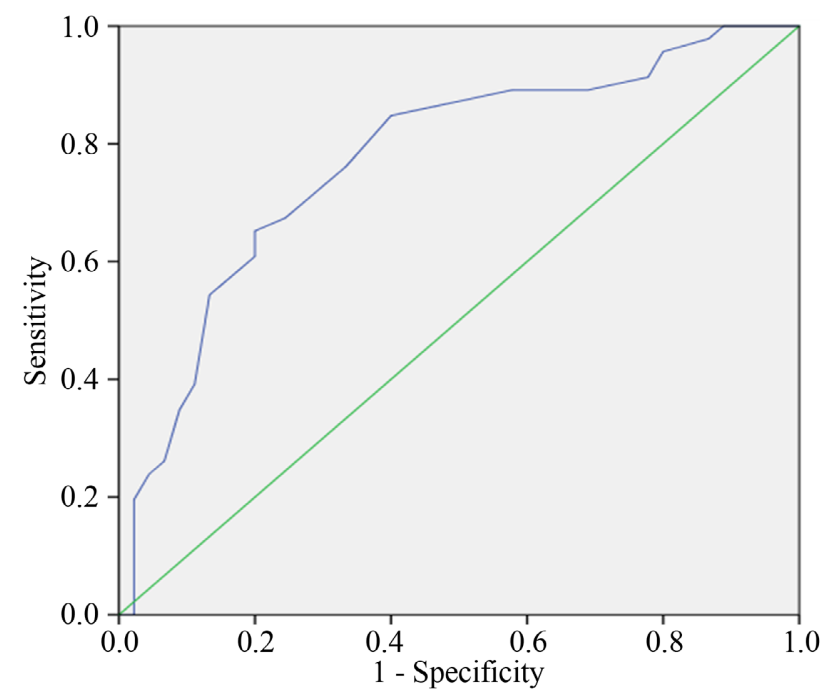

Figure 2. ROC Curve for diagnostic characteristics.

Table 3. Correlation of DCDDaily-Q-GR and MABC-2 scales.

\begin{tabular}{rcccccccc}
\hline & & \multicolumn{4}{c}{ MABC-2 DCD } & \multicolumn{2}{c}{ Total } \\
\cline { 3 - 8 } & & \multicolumn{2}{c}{ No DCD } & \multicolumn{2}{c}{ DCD } & & \\
\cline { 3 - 8 } & & N & $\%$ & N & $\%$ & n & $\%$ \\
\hline \multirow{2}{*}{ DCDDaily-Q-GR } & No DCD & 30 & $73.2 \%$ & 11 & $26.8 \%$ & 41 & $100.0 \%$ \\
& DCD & 15 & $30.0 \%$ & 35 & $70.0 \%$ & 50 & $100.0 \%$ \\
Total & & 45 & $49.5 \%$ & 46 & $50.5 \%$ & 91 & $100.0 \%$ \\
\hline
\end{tabular}




\section{Discussion}

This preliminary study is the first to have standarised the DCDDAILY-Q Dutch questionnaire in Greek and measured the psychometric properties of the translated instrument according to international guidelines [21] [26], achieved high internal consistency, good diagnostic sensitivity and specificity and high reliability test-retest.

Greek parents of children aged from 5 to 8 years old reported that they found the questionnaire easy to understand and quick to respond. The overall DCDDAILY-Q-GR scores and scores for each item effectively discriminated children with DCD and those without standard risk factors for neurological and psychiatric problems. The Questionnaire appeared to distinguish children with DCD in all three age categories [27].

Internal consistency by Cronbach's [28] has confirmed that all items in the DCDDAILY-Q-GR were homogeneous in motor coordination measurement. Cronbach's $\alpha$ (0.86) was yielded results that match those of the original Dutch version (0.85). As well as the DCDDAILY-Q has been recently validated in Spain and has shown comparable internal consistency (0.82) with the other two versions [19] [29].

Correlation analysis revealed low to strong correlations between the scales and the subscales of the questionnaire. There was no need to remove questions or change activities in order to do the standardization and the final questionnaire was very similar to the original, facilitating comparative research between countries.

Sensitivity and specificity the DCDDAILY-Q-GR were analyzed by ROC analysis (sensitivity was higher than specificity). Setting $>30$ to the DCDDaily-Q "Quality" Scale threshold and the 15th percentile to the MABC-2 Scale show that the sensitivity of the method was moderate (0.76) lower than the original (0.88) version [19]. Although sensitivity was lower than data from the American Psychological Association, it may indicate a good sorting ability [30]. Good sensitivity and specificity may have been influenced by the fact that our clinical group included children from the general population and not children from a high-risk group such as the premature group [31]. As our data have shown that the diagnostic features (sensitivity, specificity) of the translated DCDDAILY-Q-GR in Greek are satisfactory, this release will undergo further study of the diagnostic features.

An important global observation is the inability to detect DCD. The lack of familiarity of physicians with the disorder and the secondary factors caused by it [32] make this disorder "a difficult case" and as a result the diagnosis been lost or delayed [33]. In addition, the educational community is unable to identify the difficulties that arise from DCD, consequently an affected child is not referred for further testing. Great importance is the validation of assessment tools for the country of their implementation so that the DCD can be reliably diagnosed. The Greek DCDDAILY-Q-GR is a suitable tool aimed at this purpose [32]. 


\section{Strengths and Limitations}

This validation study was the first attempt to standardize a screening tool for potential DCD in Greece. This validation study was the first attempt to standardize a screening tool for potential DCD in a low health resource setting like Greece. The study design was guided by international standard and recommended processes for translation and validation, while participants were always randomly selected to minimize random biases. Still, results of the standardization processes should be translated carefully, under the light of some limitations. The questionnaire was filled in by the parents due to the young age of the children, without the presence of the researcher. This subjective assessment of the child's motor status in activities of daily living had in some cases mismatches as demonstrated by the confirmation of their motor assessment with the MABC-2. Nevertheless, this limitation is not expected to have major effects on the usability and the reliability of the questionnaire which is by nature self-assessed.

\section{Conclusions}

The validation of the DCDDaily-Q screening tool in a population of children aged from five to eight-year-old in Greece was proven to be a reliable and valid screening tool for DCD. Its use will lead to a more effective screening of the disorder in an early age and more specifically in a population attending primary education or kindergarten.

The psychometric characteristics of DCDDaily-Q-GR questionnaire can serve as a basis for identifying the difficulties of children with DCD in activities of daily living, as well as an assessment tool of appropriate and early intervention. It can also be an important tool in the hands of doctors and occupational therapists for the proper diagnosis of the disorder as it fulfills the second diagnostic criterion of the disorder.

Furthermore, no previous studies have attempted to translate and validate this screening tool in our country. In Greece, a country with no unlimited healthcare resources, there are no surveys concerning the ADL of children and it is imperative to use a reliable and cost effective tool in studies of children with mobility problems and other developmental disorders.

\section{Acknowledgements}

The authors thank the Dr. M. M. Schoemaker, Associate Professor Centre for Human Movement Science, University Medical Centre Groningen, Groningen for the permission to translate and validate the DCDDaily-Q in Greek language. We would like to thank Magdalini Flouri for her advice and support. We also thank the translators and the parents and their children who took part in the study.

\section{Authors' Contributions}

All the authors contributed significantly to the conception and the design of the 
study, to the data collection, analysis, and interpretation of the results and coordinated the translation and the cross-cultural adaptation of the questionnaire. All the authors participated in editing the manuscript and revising it critically. All the authors read and approved the final manuscript.

\section{Conflicts of Interest}

The authors do not declare any financial competing interests

\section{References}

[1] American Psychiatric Association (2013) Diagnostic Manual of Mental Disorders. 5th Edition, American Psychiatric Press Inc., Washington DC. https://doi.org/10.1176/appi.books.9780890425596

[2] American Psychiatric Association (1994) Diagnostic Criteria from DSM-IV. American Psychiatric Press Inc., Washington DC.

[3] Bingham, G.P. and Snap-Childs, W. (2018) Training Children Aged 5-10 Years in Manual Compliance Control to Improve Drawing and Handwriting. Human Movement Science, 65, 42-50. https://doi.org/10.1016/j.humov.2018.04.002

[4] Blank, R., et al. (2019) International Clinical Practice Recommendations on the Definition, Diagnosis, Assessment, Intervation, and Psychosocial Aspects of Developmental Coordination Disorder. Developmental Medical and Child Neurology, 61, 242-285. https://doi.org/10.1111/dmcn.14132

[5] Summers, J., Larkin, D. and Dewey, D. (2008) Activities of Daily Living in Children with Developmental Coordination Disorders: Dressing, Personal Hygiene and Eating Skills. Human Movement Science, 27, 215-229. https://doi.org/10.1016/j.humov.2008.02.002

[6] Dunford, C., Missiuna, C., Street, E. and Sibert, J. (2005) Children's Perceptions of the Impact of Developmental Coordination Disorders on Activities of Daily Living. British Journal of Occupational Therapy, 68, 207-214. https://doi.org/10.1177/030802260506800504

[7] Van der Linde, B.W., et al. (2015) Activities of Daily Living in Children with Developmental Coordination Disorder: Performance, Learning, and Participation. Physical Therapy, 95, 1496-1506. https://doi.org/10.2522/ptj.20140211

[8] Brown, T. and Lalor, A. (2009) The Movement Assessment Battery for ChildrenSecond Edition (MABC-2): A Review and Critique. Physical and Occupational Therapy in Pediatrics, 29, 86-103. https://doi.org/10.1080/01942630802574908

[9] Gomez, A. and Sirigu, A. (2015) Developmental Coordination Disorder: Core Sensori-Motor Deficits, Neurobiology and Etiology. Neuropsychologia, 79, 272-287. https://doi.org/10.1016/j.neuropsychologia.2015.09.032

[10] Visser, J. (2003) Developmental Coordination Disorder: A Review of Research on Subtypes and Comorbidities. Revista Humam Movement Science, 22, 479-493. https://doi.org/10.1016/j.humov.2003.09.005

[11] Zwicker, J.G., Missiuna, C., Harris, S.R. and Boyd, L.A. (2012) Developmental Coordination Disorders: A Review and Update. European Journal of Paediatric Neurology, 16, 573-581. https://doi.org/10.1016/j.ejpn.2012.05.005

[12] Cousins, M. and Smyth, M.M. (2003) Developmental Coordination Impairments in Adulthood. Human Movement Science, 22, 433-459. https://doi.org/10.1016/j.humov.2003.09.003

[13] Lingam, R., et al. (2009) Prevalence of Developmental Coordination Disorder Using 
the DSM-IV at 7 Years of Age: A UK Population-Based Study. Pediatrics, 4, 693 700. https://doi.org/10.1542/peds.2008-1770

[14] Griffiths, A., Toovey, R., Morgan, P.E. and Spittle, A.J. (2018) Psychometric Properties of Gross Motor Assessment Tools for Children: A Systematic Review. BMJ Open, 8, e021734. https://doi.org/10.1136/bmjopen-2018-021734

[15] Maxim, L.D., Niebo, R. and Utell, M.J. (2014) Screening Tests: A Review with Examples. Inhalation Toxicology, 13, 811-828.

https://doi.org/10.3109/08958378.2014.955932

[16] Brämer, G.R. (1988) International Statistical Classification of Diseases and Related Health Problems. 10th Revision. World Health Statistics Quarterly, 41, 32-36.

[17] van der Linde, B.W., van Netten, J.J., Otten, B.E., Postema, K., Geuze, R.H. and Schoemaker, M.M. (2013) Development and Psychometric Properties of the DCDDaily: A New Test for Clinical Assessment of Capacity in Activities of Daily Living in Children with Developmental Coordination Disorder. Clinical Rehabilitation, 27, 834844. https://doi.org/10.1177/0269215513481227

[18] Kaiser, M.-L., Albaret, J. and Cantell, M. (2015) Assessment of the Participation of the Children with a Developmental Coordination Disorder (DCD): A Review of the Questionnaires Addressed to Parents and/or Teachers. Journal of Child and Adolescent Behavior, 3, 234.

[19] Linde, B.W., et al. (2014) Psychometric Properties of the DCDDaily-Q: A New Parental Questionnaire on Children's Performance in Activities of Daily Living. Research in Developmental Disabilities, 35, 1711-1719.

https://doi.org/10.1016/j.ridd.2014.03.008

[20] Iraggorri, N. and Spackman, E. (2018) Assessing the Value of Screening Tools: Reviewing the Challenges and Opportunities of Cost-Effectiveness Analysis. Public Health Reviews, 39, 17. https://doi.org/10.1186/s40985-018-0093-8

[21] Beaton, D.E., Bombardier, C., Guillemin, F. and Ferraz, M.B. (2000) Guidelines for the Process of Cross-Cultural Adaptation of Self-Report Measures. Spine (Phila Pa 1976), 25, 3186-3191. https://doi.org/10.1097/00007632-200012150-00014

[22] Slater, L.M., Hillier, S.L. and Civetta, L.R. (2010) The Clinimetric Properties of Performance-Based Gross Motor Tests Used for Children with Developmental Coordination Disorder: A Systematic Review. Pediatric Physical Therapy, 22, 170-179. https://doi.org/10.1097/PEP.0b013e3181dbeff0

[23] Henderson, S., Sugden, D. and Barnett, A. (2007) Movement Assessment Battery for Children. Second Edition, Pearson, London. https://doi.org/10.1037/t55281-000

[24] Van Waelvelde, H., Peersman, W., Lenoir, M. and Smits-Engelsman, B. (2007) The Reliability of the Movement Assessment Battery for Children for Preschool Children with Mild to Moderate Motor Impairment. Clinical Rehabilitation, 5, 465-470. https://doi.org/10.1177/0269215507074052

[25] Wuang, Y., Su, J. and Su, C. (2012) Reliability and Responsiveness of the Movement Assessment Battery for Children-Second Edition Test in Children with Developmental Coordination Disorder. Developmental Medicine and Child Neurology, 54, 160-165. https://doi.org/10.1111/j.1469-8749.2011.04177.x

[26] Guillemin, F., Bombardier, C. and Beaton, D. (1993) Cross-Cultural Adaptation of Health-Related Quality of Life Measures: Literature Review and Proposed Guidelines. Journal of Clinical Epidemiology, 46, 1417-1432. https://doi.org/10.1016/0895-4356(93)90142-N

[27] Krabbe, P.F. (2017) The Measurement of Health and Health Status. Academic Press, Cambridge, 113-134. https://doi.org/10.1016/B978-0-12-801504-9.00007-6 
[28] Taber, K.S. (2017) The Use of Cronbach's Alpha When Developing and Reporting Research Instruments in Science Education. Research in Science Education, 48, 1273-1296. https://doi.org/10.1007/s11165-016-9602-2

[29] Montes-Montes, R., Delgado-Lobete, L., Pereira, J., Schoemaker, M., Santos-delRiego, S. and Pousada, T. (2020) Identifying Children with Developmental Coordination Disorder via Parental Questionnaires. Spanish Reference Norms for the DCDDaily-Q-ES and Correlation with the DCDQ-ES. International Journal of Environmental Research and Public Health, 17, 555. https://doi.org/10.3390/ijerph17020555

[30] Hunsley, J. and Meyer, G.J. (2003) The Incremental Validity of Psychological Testing and Assessment: Conceptual, Methodological, and Statistical Issues. Psychological Assessment, 4, 446-455. https://doi.org/10.1037/1040-3590.15.4.446

[31] Trevethan, R. (2017) Sensitivity, Specificity, and Predictive Values: Foundations, Pliabilities, and Pitfalls in Research and Practice. Frontiers in Public Health, 5, 307. https://doi.org/10.3389/fpubh.2017.00307

[32] Harris, S.R., Mickelson, E.C. and Zwicker, J.G. (2015) Diagnosis and Management of Developmental Coordination Disorder. CMAJ, 187, 659-665. https://doi.org/10.1503/cmaj.140994

[33] Wilson, P.H., Ruddock, S., Engelsman, B.S. and Polatajko, H. (2012) Understanding Performance Deficits in Developmental Coordination Disorders: A Meta-Analysis of Recent Research. Developmental Medicine and Child Neurology, 55, 217-228. https://doi.org/10.1111/j.1469-8749.2012.04436.x 


\section{Appendix}

Table A1. Frequency and \% frequency of DCDDaily scale questions (Participation).

\begin{tabular}{|c|c|c|c|c|c|c|c|c|c|c|c|}
\hline & \multicolumn{11}{|c|}{ Participation } \\
\hline & \multicolumn{2}{|c|}{ 1-regularly } & \multicolumn{4}{|c|}{ 2-sometimes } & \multicolumn{3}{|c|}{ 3-seldom } & \multicolumn{2}{|c|}{$\begin{array}{c}\text { 4-not } \\
\text { yet/never }\end{array}$} \\
\hline & $\mathbf{n}$ & $\%^{1}$ & $\%^{2}$ & $\mathbf{N}$ & $\%$ & $\%$ & $\mathbf{n}$ & $\%$ & $\%$ & $\mathbf{N}$ & $\%$ \\
\hline P1 & 41 & $21.8 \%$ & $25.3 \%$ & 86 & $45.7 \%$ & $53.1 \%$ & 35 & $18.6 \%$ & $21.6 \%$ & 26 & $13.8 \%$ \\
\hline P2 & 34 & $18.0 \%$ & $22.1 \%$ & 64 & $33.9 \%$ & $41.6 \%$ & 56 & $29.6 \%$ & $36.4 \%$ & 35 & $18.5 \%$ \\
\hline P3 & 177 & $93.2 \%$ & $93.2 \%$ & 11 & $5.8 \%$ & $5.8 \%$ & 2 & $1.1 \%$ & $1.1 \%$ & 0 & $0.0 \%$ \\
\hline P4 & 149 & $78.0 \%$ & $78.0 \%$ & 35 & $18.3 \%$ & $18.3 \%$ & 7 & $3.7 \%$ & $3.7 \%$ & 0 & $0.0 \%$ \\
\hline P5 & 167 & $87.4 \%$ & $87.9 \%$ & 21 & $11.0 \%$ & $11.1 \%$ & 2 & $1.0 \%$ & $1.1 \%$ & 1 & $0.5 \%$ \\
\hline P6 & 184 & $96.3 \%$ & $96.3 \%$ & 7 & $3.7 \%$ & $3.7 \%$ & 0 & $0.0 \%$ & $0.0 \%$ & 0 & $0.0 \%$ \\
\hline P7 & 124 & $64.9 \%$ & $70.5 \%$ & 33 & $17.3 \%$ & $18.8 \%$ & 19 & $9.9 \%$ & $10.8 \%$ & 15 & $7.9 \%$ \\
\hline P8 & 163 & $85.3 \%$ & $85.8 \%$ & 22 & $11.5 \%$ & $11.6 \%$ & 5 & $2.6 \%$ & $2.6 \%$ & 1 & $0.5 \%$ \\
\hline P9 & 59 & $30.9 \%$ & $34.7 \%$ & 71 & $37.2 \%$ & $41.8 \%$ & 40 & $20.9 \%$ & $23.5 \%$ & 21 & $11.0 \%$ \\
\hline P10 & 148 & $77.9 \%$ & $78.3 \%$ & 26 & $13.7 \%$ & $13.8 \%$ & 15 & $7.9 \%$ & $7.9 \%$ & 1 & $0.5 \%$ \\
\hline P11 & 167 & $87.9 \%$ & $87.9 \%$ & 21 & $11.1 \%$ & $11.1 \%$ & 2 & $1.1 \%$ & $1.1 \%$ & 0 & $0.0 \%$ \\
\hline P12 & 147 & $77.4 \%$ & $78.6 \%$ & 35 & $18.4 \%$ & $18.7 \%$ & 5 & $2.6 \%$ & $2.7 \%$ & 3 & $1.6 \%$ \\
\hline P13 & 102 & $53.4 \%$ & $55.7 \%$ & 68 & $35.6 \%$ & $37.2 \%$ & 13 & $6.8 \%$ & $7.1 \%$ & 8 & $4.2 \%$ \\
\hline P14 & 176 & $92.1 \%$ & $92.1 \%$ & 12 & $6.3 \%$ & $6.3 \%$ & 3 & $1.6 \%$ & $1.6 \%$ & 0 & $0.0 \%$ \\
\hline P15 & 139 & $72.8 \%$ & $72.8 \%$ & 47 & $24.6 \%$ & $24.6 \%$ & 5 & $2.6 \%$ & $2.6 \%$ & 0 & $0.0 \%$ \\
\hline P16 & 107 & $56.3 \%$ & $59.4 \%$ & 58 & $30.5 \%$ & $32.2 \%$ & 15 & $7.9 \%$ & $8.3 \%$ & 10 & $5.3 \%$ \\
\hline P17 & 106 & $55.8 \%$ & $60.6 \%$ & 51 & $26.8 \%$ & $29.1 \%$ & 18 & $9.5 \%$ & $10.3 \%$ & 15 & $7.9 \%$ \\
\hline P18 & 96 & $50.3 \%$ & $52.5 \%$ & 56 & $29.3 \%$ & $30.6 \%$ & 31 & $16.2 \%$ & $16.9 \%$ & 8 & $4.2 \%$ \\
\hline P19 & 32 & $16.8 \%$ & $26.9 \%$ & 40 & $21.1 \%$ & $33.6 \%$ & 47 & $24.7 \%$ & $39.5 \%$ & 71 & $37.4 \%$ \\
\hline P20 & 70 & $37.4 \%$ & $42.4 \%$ & 65 & $34.8 \%$ & $39.4 \%$ & 30 & $16.0 \%$ & $18.2 \%$ & 22 & $11.8 \%$ \\
\hline P21 & 134 & $70.5 \%$ & $70.5 \%$ & 49 & $25.8 \%$ & $25.8 \%$ & 7 & $3.7 \%$ & $3.7 \%$ & 0 & $0.0 \%$ \\
\hline P22 & 119 & $62.3 \%$ & $63.3 \%$ & 47 & $24.6 \%$ & $25.0 \%$ & 22 & $11.5 \%$ & $11.7 \%$ & 3 & $1.6 \%$ \\
\hline P23 & 41 & $21.6 \%$ & $33.9 \%$ & 31 & $16.3 \%$ & $25.6 \%$ & 49 & $25.8 \%$ & $40.5 \%$ & 69 & $36.3 \%$ \\
\hline
\end{tabular}

$\%^{1}$ Percentage of total, $\%^{2}$ Percentage not yet selected/total.

Table A2. Frequency and \% frequency of DCDDaily scale questions (Quality).

\begin{tabular}{ccccccc}
\hline & \multicolumn{9}{c}{ Quality } \\
\cline { 2 - 7 } & \multicolumn{2}{c}{ Well } & \multicolumn{2}{c}{$\begin{array}{l}\text { Sometimes well and at } \\
\text { other times not as well }\end{array}$} & \multicolumn{2}{c}{$\begin{array}{l}\text { Not very well } \\
\text { most of time }\end{array}$} \\
\cline { 2 - 7 } & $\mathrm{N}$ & $\%$ & $\mathrm{~N}$ & $\%$ & $\mathrm{~N}$ & $\%$ \\
\hline Q1 & $\mathbf{8 5}$ & $\mathbf{5 0 . 6 \%}$ & 76 & $45.2 \%$ & 7 & $4.2 \%$ \\
\hline
\end{tabular}




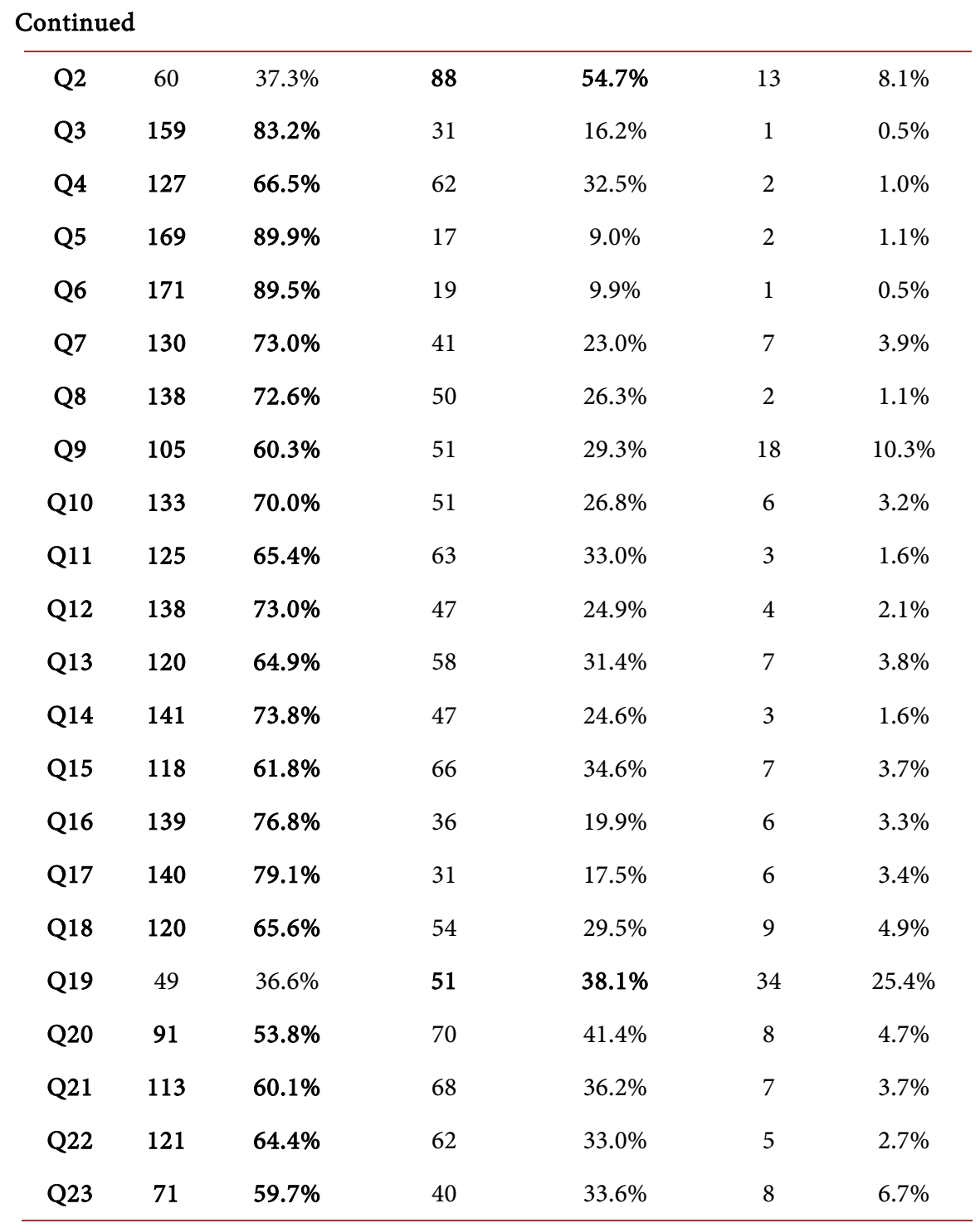

Table A3. Frequency and\% frequency of DCDDaily scale questions (Acquisition).

\begin{tabular}{|c|c|c|c|c|}
\hline & \multicolumn{4}{|c|}{ Acquisition } \\
\hline & \multicolumn{2}{|c|}{ No } & \multicolumn{2}{|c|}{ Yes } \\
\hline & $\mathrm{n}$ & $\%$ & $\mathbf{n}$ & $\%$ \\
\hline A1 & 169 & $89.4 \%$ & 20 & $10.6 \%$ \\
\hline $\mathrm{A} 2$ & 168 & $89.4 \%$ & 20 & $10.6 \%$ \\
\hline A3 & 184 & $96.3 \%$ & 7 & $3.7 \%$ \\
\hline A4 & 177 & $92.7 \%$ & 14 & $7.3 \%$ \\
\hline A5 & 184 & $96.3 \%$ & 7 & $3.7 \%$ \\
\hline A6 & 183 & $96.3 \%$ & 7 & $3.7 \%$ \\
\hline A7 & 179 & $95.2 \%$ & 9 & $4.8 \%$ \\
\hline A8 & 181 & $94.8 \%$ & 10 & $5.2 \%$ \\
\hline
\end{tabular}




\begin{tabular}{ccccc} 
Continued & & & & \\
\hline A9 & 176 & $93.1 \%$ & 13 & $6.9 \%$ \\
A10 & 174 & $91.1 \%$ & 17 & $8.9 \%$ \\
A11 & 176 & $92.1 \%$ & 15 & $7.9 \%$ \\
A12 & 184 & $96.3 \%$ & 7 & $3.7 \%$ \\
A13 & 178 & $94.2 \%$ & 11 & $5.8 \%$ \\
A14 & 180 & $94.7 \%$ & 10 & $5.3 \%$ \\
A15 & 174 & $91.1 \%$ & 17 & $8.9 \%$ \\
A16 & 184 & $96.3 \%$ & 7 & $3.7 \%$ \\
A17 & 182 & $95.3 \%$ & 9 & $4.7 \%$ \\
A18 & 176 & $92.1 \%$ & 15 & $7.9 \%$ \\
A19 & 161 & $87.5 \%$ & 23 & $12.5 \%$ \\
A20 & 179 & $94.2 \%$ & 11 & $5.8 \%$ \\
A21 & 173 & $90.6 \%$ & 18 & $9.4 \%$ \\
A22 & 177 & $92.7 \%$ & 14 & $7.3 \%$ \\
A23 & 168 & $92.8 \%$ & 13 & $7.2 \%$ \\
\hline & & & & \\
\hline & $17 \%$ & $9.9 \%$ & \\
\hline
\end{tabular}

Table A4. Scale and sub-scale correlations DCDDaily-Q-GR.

\begin{tabular}{|c|c|c|c|c|c|c|c|c|c|c|c|c|c|}
\hline & & \multicolumn{4}{|c|}{ Participation } & \multicolumn{4}{|c|}{ Quality } & \multicolumn{4}{|c|}{ Acquisition } \\
\hline & & FM & SC/SM & P/GM & TP & FM & SC/SM & P-GM & TQ & FM & SC/SM & P-GM & TA \\
\hline \multirow{2}{*}{ Fine motor } & $\mathbf{R}$ & 1.00 & 0.30 & 0.32 & 0.60 & 0.58 & 0.28 & 0.23 & 0.45 & 0.31 & 0.22 & 0.19 & 0.27 \\
\hline & $\mathbf{P}$ & & $<0.001$ & $<0.001$ & $<0.001$ & $<0.001$ & $<0.001$ & 0.00 & $<0.001$ & $<0.001$ & 0.00 & 0.01 & $<0.001$ \\
\hline \multirow{2}{*}{$\begin{array}{l}\text { Self Care/self } \\
\text { Maintenance }\end{array}$} & $\mathbf{R}$ & 0.30 & 1.00 & 0.47 & 0.82 & 0.32 & $0.179^{*}$ & -0.01 & 0.20 & 0.28 & 0.27 & 0.22 & 0.29 \\
\hline & $\mathrm{P}$ & $<0.001$ & & 0.00 & 0.00 & $<0.001$ & 0.01 & 0.94 & 0.01 & $<0.001$ & $<0.001$ & 0.00 & $<0.001$ \\
\hline \multirow{2}{*}{ Play/Gross motor } & $\mathbf{R}$ & 0.32 & 0.47 & 1.00 & 0.83 & 0.30 & 0.09 & 0.05 & 0.18 & 0.13 & 0.15 & 0.26 & 0.20 \\
\hline & $\mathbf{P}$ & $<0.001$ & 0.00 & & 0.00 & $<0.001$ & 0.19 & 0.52 & 0.01 & 0.07 & 0.03 & $<0.001$ & 0.01 \\
\hline \multirow{2}{*}{ Total Participation } & $\mathbf{R}$ & 0.60 & 0.82 & 0.83 & 1.00 & 0.48 & 0.22 & 0.09 & 0.32 & 0.30 & 0.28 & 0.29 & 0.32 \\
\hline & $P$ & $<0.001$ & 0.00 & 0.00 & & $<0.001$ & 0.00 & 0.23 & $<0.001$ & $<0.001$ & $<0.001$ & $<0.001$ & $<0.001$ \\
\hline \multirow{2}{*}{ Fine motor } & $\mathbf{R}$ & 0.58 & 0.32 & 0.30 & 0.48 & 1.00 & 0.57 & 0.57 & 0.80 & 0.57 & 0.44 & 0.39 & 0.52 \\
\hline & $\mathbf{P}$ & $<0.001$ & 0.00 & 0.00 & 0.00 & & $<0.001$ & $<0.001$ & $<0.001$ & $<0.001$ & $<0.001$ & $<0001$ & $<0.001$ \\
\hline \multirow{2}{*}{$\begin{array}{l}\text { Self Care/ self } \\
\text { Maintenance }\end{array}$} & $\mathbf{R}$ & 0.28 & 0.18 & 0.09 & 0.22 & 0.57 & 1.00 & 0.35 & 0.82 & 0.36 & 0.51 & 0.39 & 0.48 \\
\hline & $\mathbf{P}$ & $<0.001$ & 0.01 & 0.19 & 0.00 & 0.00 & & $<0.001$ & $<0.001$ & $<0.001$ & $<0.001$ & $<0.001$ & $<0.001$ \\
\hline \multirow{2}{*}{ Play/Gross motor } & $\mathbf{R}$ & 0.23 & -0.01 & 0.05 & 0.09 & 0.36 & 0.353 & 1.00 & 0.74 & 0.26 & 0.25 & 0.42 & 0.34 \\
\hline & $\mathbf{P}$ & 0.00 & 0.94 & 0.52 & 0.23 & 0.00 & 0.00 & & $<0.001$ & $<0.001$ & $<0.001$ & $<0.001$ & $<0.001$ \\
\hline \multirow{2}{*}{ Total Quality } & $\mathbf{R}$ & 0.45 & 0.20 & 0.18 & 0.32 & 0.80 & 0.82 & 0.74 & 1.00 & 0.50 & 0.51 & 0.51 & 0.57 \\
\hline & $P$ & 0.00 & 0.01 & 0.01 & 0.00 & 0.00 & 0.00 & 0.00 & & $<0.001$ & $<0.001$ & $<0.001$ & $<0.001$ \\
\hline
\end{tabular}


G. Dragoumanaki et al.

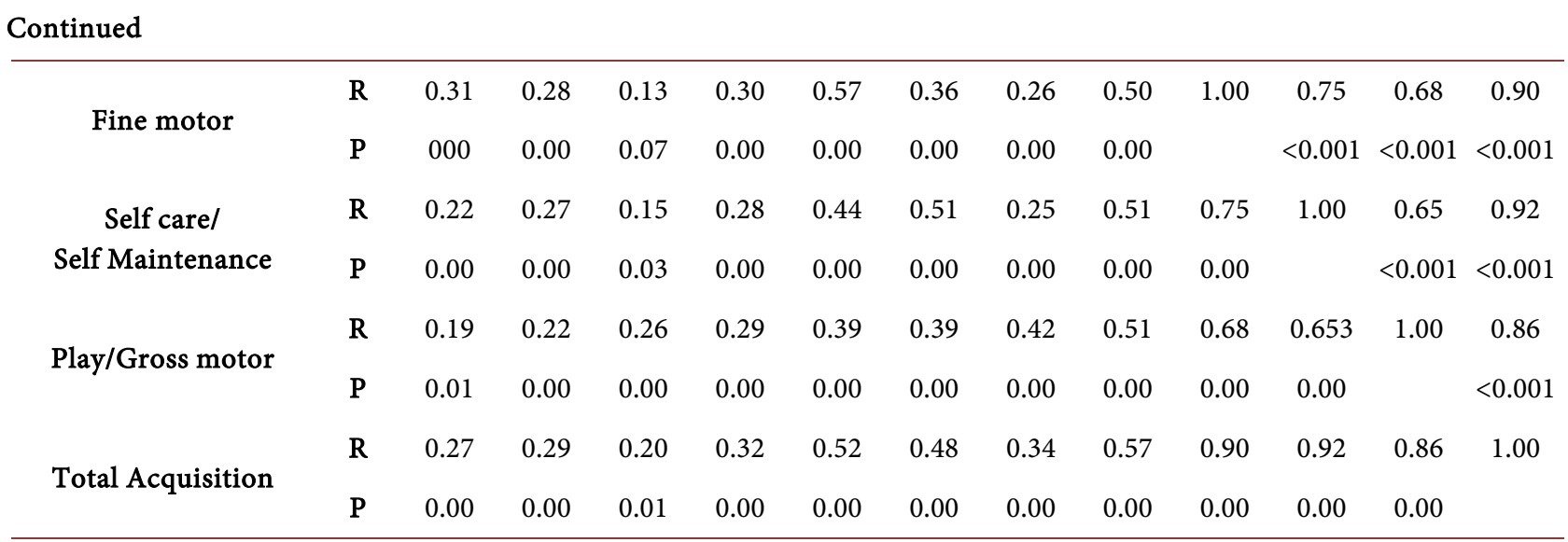

